\title{
REVIEW
}

\section{Urine nandrolone metabolites: false positive doping test?}

\section{R M N Kohler, M I Lambert}

Br J Sports Med 2002;36:325-329

The aim of this review is to analyse the studies on nandrolone metabolism to determine if it is possible for an athlete to test positive for nandrolone without having ingested or injected nandrolone.

T he anabolic androgenic steroid 19. nortestosterone, also called nandrolone, was first synthesised by Birch in 1950. ${ }^{1}$ Nandrolone has an anabolic effect, and is used in the treatment of certain chronic diseases. ${ }^{1-3}$ The use of nandrolone by athletes became popular in the late 1950s. ${ }^{4}$ Athletes use nandrolone in an oral or injectable form to increase muscle strength and improve performance. ${ }^{5}$ As a result of the potential performance enhancing benefits ${ }^{6}$ and potential health risks associated with anabolic steroid use, the International Olympic Committee (IOC) prohibited the use of nandrolone in sport in 1976.

"A doping offence for nandrolone was defined as a concentration of NA in human urine exceeding $2 \mathrm{ng} / \mathrm{ml}$ in men and 5 $\mathrm{ng} / \mathrm{ml}$ in women"

When nandrolone is ingested or injected by humans subjects, three metabolites of nandrolone can be isolated and measured in the urine by gas chromatography-mass spectrometry. These metabolites have been identified as 19norandrosterone (NA; 3 $\alpha$-hydroxy- $\alpha \alpha$-oestran17-one), 19-noretiocholanolone ( $3 \alpha$-hydroxy- $5 \beta$ oestran-17-one), and 19-norepiandrosterone (3 $\beta$-hydroxy- $\alpha \alpha$-oestran-17-one). ${ }^{8-13}$ These metabolites are isomeric compounds, having the same chemical composition and molecular mass but different chemical structure. NA is usually the most abundant urine metabolite of nandrolone. ${ }^{9-13}$ The presence of these metabolites in the urine forms the basis of doping analysis for the illegal use of nandrolone by athletes. ${ }^{8}{ }^{12} 14-16$ This was based on the premise that these urine metabolites could only have been derived from exogenous nandrolone. A study in 1982 appeared to have found NA, or a similar compound, in the urine of athletes who had not used nandrolone. ${ }^{8}$ In 1996, the IOC stated that a critical concentration for nandrolone metabolites in the urine had been established. A doping offence for nandrolone was defined as a concentration of NA in human urine exceeding $2 \mathrm{ng} / \mathrm{ml}$ in men and 5 $\mathrm{ng} / \mathrm{ml}$ in women. ${ }^{17}$

"Recently, the possibility of false positive tests for nandrolone has been raised."
Recently, the possibility of false positive tests for nandrolone has been raised. Explanations for false positive tests have included supplement contamination $^{18}$ and endogenous production of nandrolone and regulation of metabolic pathways of nandrolone metabolism by various physiological factors and supplement interventions. The aim of this review is to analyse the studies on nandrolone metabolism with the overall goal of determining whether it is indeed possible for an athlete to test positive for nandrolone without having either ingested or injected nandrolone. The question of a positive test resulting from nutritional supplements ${ }^{14}$ and food contamination $^{19} 20$ is beyond the scope of this review.

\section{EVIDENCE FOR ENDOGENOUS NA}

The origin of endogenous NA in the urine of athletes who have not knowingly ingested or injected nandrolone is central to resolving the question of whether it is possible to have a false positive test. The first study to suggest that NA could be found in the urine of people free of exogenous nandrolone was a study on laboratory staff $(\mathrm{n}=$ 14). ${ }^{8}$ Their urine was analysed using isotope dilution mass spectrometry, and NA or a similar compound was suspected. This suspicion was based on the detection of a small peak for the ion at $\mathrm{m} / \mathrm{z}$ $256 .^{8}$ In retrospect, this signal may have been caused by interference of other endogenous compounds (noise) and perhaps represents a false positive finding. The authors acknowledged the limitations of the study, the analytical technique lacking specificity and sensitivity.

Studies in 1988 and 1990 again raised the possibility of endogenous NA in the urine of humans. Kicman and Brooks ${ }^{21}$ used radioimmunoassay and measured NA in the urine of men and women, who were supposedly free of exogenous nandrolone, ranging from 3.8 to 49.4 $\mathrm{ng} / \mathrm{ml}$. However, these data should be interpreted with caution as it could be argued that the analytical technique again lacks both specificity and sensitivity. Debruyckere et $a l^{11}$ measured NA in the urine of three subjects at concentrations of 9, 14, and $37 \mathrm{ng} / \mathrm{ml}{ }^{11}$ These results were later attributed to nandrolone contaminated meat which the subjects may have eaten. ${ }^{192}$

In 1996, the IOC declared that the presence of a small amount of NA in the urine was not considered to constitute a doping offence. ${ }^{17}$ This suggests that they acknowledged the possibility

Abbreviations: IOC, International Olympic Committee; NA, 19-norandrosterone; GC-C-IRMS, gas chromatography-combustion-isotope ratio mass spectrometry 


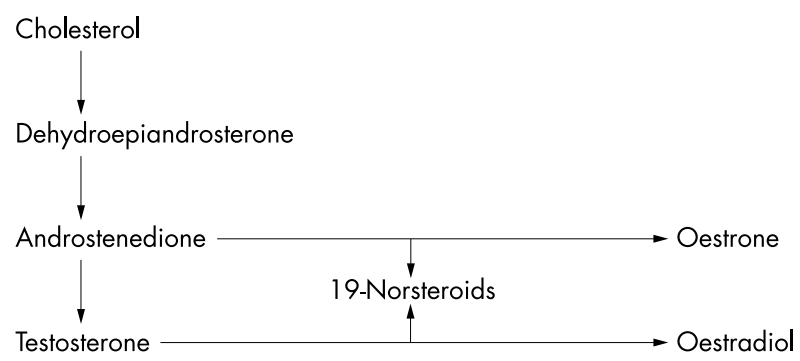

Figure 1 The androgen biosynthetic pathway and the proposed aromatisation of androgen to oestrogen with the formation of 19-norsteroid intermediates.

of endogenous NA production. It can only be assumed that this decision was reached on the basis of data collected by IOC laboratories during routine drug testing, as the scientific evidence at the time was equivocal. In the late 1990s, analytical procedures for the detection and quantification of steroid metabolites in urine had become increasingly sensitive. ${ }^{23}$ This may have accounted for an appreciable number of positive urine samples for NA being analysed in certain anti-doping laboratories. Many of the positive samples were from participants of sports that had previously not been associated with anabolic steroid use. ${ }^{1}$ Further research with more sensitive equipment was undertaken to determine if NA could be produced naturally by the human body. This research showed convincing evidence that NA was found in the urine of subjects free of exogenous nandrolone. ${ }^{15} 1824-28$ The urine NA concentrations in these studies ranged from 0.01 to 1.79 $\mathrm{ng} / \mathrm{ml}$. In a study by Galan Martin et al, ${ }^{29}$ high NA concentrations in five sportspeople $(4,5,6,8$, and $14 \mathrm{ng} / \mathrm{ml})$ were measured. One woman in the study, who was postmenopausal, had a NA concentration of $22 \mathrm{ng} / \mathrm{ml}$. It could be argued that these athletes had administered nandrolone. ${ }^{29}$ These results are difficult to explain and perhaps further investigation of these subjects is necessary before a definite opinion can be formed.

\section{METABOLISM OF NA}

\section{Aromatisation}

Metabolic pathways for the endogenous production of NA in the human body need to be considered. Under normal circumstances, testosterone is aromatised to oestrogen by the aromatase enzyme complex. ${ }^{30}$ Androstenedione, the direct precursor of testosterone, is also aromatised to oestrogen by the aromatase enzyme. ${ }^{31}{ }^{32}$ The important step in this metabolic process is the removal of the methyl group from the 19th carbon of either testosterone or androstenedione. Nandrolone differs structurally from testosterone and androstenedione in lacking the methyl group at the 19th carbon, and it is additionally different from androstenedione in substitution of a ketone group for an hydroxy group at the 17th carbon. Is it feasible that 19-norsteroids (nandrolone and metabolites) are intermediates in the aromatisation process? (fig l).

Animal studies, in vitro experiments, and observations in humans, particularly pregnant women, add support to the proposal that 19-norsteroids are intermediates in the aromatisation of androgens to oestrogen. ${ }^{815} 1821252633-37$ Oestrogen concentrations in women increase significantly both at the time of ovulation and during pregnancy. ${ }^{26}{ }^{38}$ Raised urine NA concentrations have recently been identified in women at the time of ovulation ${ }^{26}{ }^{39}$ and during pregnancy. ${ }^{26}$ Mareck-Engelke et $a l^{40}$ reported that during pregnancy the concentration of NA in human urine may reach $20 \mathrm{ng} / \mathrm{ml}$. In these cases, pregnancy is confirmed with a blood test for human chorionic gonadotrophin.
A recent study by Reznik et al $^{25}$ examined the sequelae of giving human chorionic gonadotrophin to 10 men. Human chorionic gonadotrophin increases serum testosterone in healthy $\operatorname{men}^{41-43}$ and stimulates the aromatase enzyme, causing a gradual increase in serum oestrogen..$^{44} 45$ The serum testosterone and oestrogen increased in the 10 subjects after human chorionic gonadotrophin administration, and NA excretion in the urine increased by $250 \%$. It may be concluded from this study that the increase in nandrolone biosynthesis was possibly associated with the increased aromatisation of testosterone to oestrogen.

"Factors that could increase the flux of androgen precursors through the testosterone biosynthetic pathway could theoretically increase the amount of nandrolone produced."

Although the pathways proposed are theoretical, the available evidence suggests that it is possible for the flux of androgen precursors through the testosterone biosynthetic pathway to result in the production of endogenous nandrolone. Therefore it can be assumed that factors that could increase the flux of androgen precursors through the testosterone biosynthetic pathway could theoretically increase the amount of nandrolone produced.

\section{FACTORS WITH THE POTENTIAL TO AFFECT NA METABOLISM}

Genetics

There is a wide range of serum testosterone concentrations in men, ${ }^{32}$ suggesting large genetic interindividual and intraindividual variability in sex steroid production and excretion over a 24 hour period. ${ }^{46}$ The possibility therefore exists that there is a variable rate of NA excretion. ${ }^{1}$ Indeed, endogenous NA urine excretion in a male athlete varied by $680 \%$ over a three month period $^{1}$ and in another subject by $72 \%$ over a 24 hour period. ${ }^{15}$ The enzyme complex 17 $\beta$-hydroxysteroid dehydrogenase, which is responsible for converting androstenedione into testosterone, and the aromatase enzyme complex, which converts testosterone into oestrogen, occur in muscle and fat. ${ }^{31}{ }^{47}$ Therefore, it is conceivable that people with higher muscle and fat content may be more proficient in the production of 19-norsteroid intermediates. The aromatase enzyme complex per se can also show considerable genetic variability in expression and activity in certain people, ${ }^{48}$ with increased activity of the aromatase enzyme producing larger amounts of oestrogen. This prompts the question of whether genetic upregulation of the aromatisation process in these people increases the production of 19-norsteroids.

\section{Exercise}

Intense exercise has been associated with raised levels of NA in the urine. ${ }^{127}{ }^{28}$ Le Bizec et $a l^{28}$ studied professional soccer players over 19 months and collected 385 urine samples. Urine NA concentrations after soccer games were significantly higher than before games. For NA concentrations after games, $70 \%$ of the urine samples were below $0.1 \mathrm{ng} / \mathrm{ml}$, and $20 \%$ were between 0.1 and $0.2 \mathrm{ng} / \mathrm{ml}$. NA in four urine samples were above $1.0 \mathrm{ng} / \mathrm{ml}$, the maximum value being $1.79 \mathrm{ng} / \mathrm{ml} .{ }^{28}$ When urine is tested for banned substances and the specific gravity of the urine sample is measured above 1.020, urine metabolite concentrations are adjusted by a correction factor. ${ }^{23}$ This analysis is based on the premise that urine flow rate and urine metabolite excretion remain constant during and directly after exercise. However, this is an erroneous assumption as it has been shown that excretion of pseudoephedrine after exercise was increased in subjects in whom urine volume remained constant. ${ }^{49}$ Thus urine metabolite excretion may not remain constant during and directly after exercise, and 
random urine sample collection after exercise may be unreliable. ${ }^{15}{ }^{42}$ A more accurate measure would be to collect a urine sample over a 24 hour period, allowing the calculation of excretion rates of urine metabolites. ${ }^{15}$ However, this is not practical, particularly when testing for drug use in sport.

The serum androgen response to exercise in athletes can vary according to the type, duration, and intensity of the exercise task. ${ }^{50-56}$ Serum concentrations of testosterone, androstenedione, and dehydroepiandrosterone increase with short term, intense exercise as the result of increased testicular production by an unknown mechanism. ${ }^{57}$ An increase in serum testosterone after exercise may also be caused by a decrease in the plasma volume ${ }^{58}$ or a decrease in hepatic clearance. ${ }^{54}$ The effect of exercise on serum oestrogen is also extremely variable. $^{53}$

\section{"A urine specimen collected after high intensity exercise could have a higher concentration of NA"}

It is conceivable that the increase in circulating androgens in people participating in short duration, high intensity exercise could result in the stimulation of the aromatase enzyme complex, resulting in an absolute increase in the amount of $\mathrm{NA}$ in the urine. Therefore, there are sufficient data ${ }^{127}$ to suggest that a urine specimen collected after high intensity exercise could have a higher concentration of NA for reasons other than dehydration.

\section{Trauma and hypoglycaemic stress}

As yet, no study has investigated the possible effect that traumatic stress (musculoskeletal injury) may have on 19norsteroid metabolism. Interestingly, two international male athletes, one an international rugby player ${ }^{59}$ and the other a paraOlympian (B Frasure, personal communication), recently tested positive for NA above $2 \mathrm{ng} / \mathrm{ml}$, after both having suffered significant injuries just before passing a urine sample for drug testing. Both athletes claimed to be innocent of a doping offence. The concentration of NA in the urine samples of both athletes was about $6 \mathrm{ng} / \mathrm{ml}$, which is slightly above the IOC cut off concentration for men $(2 \mathrm{ng} / \mathrm{ml})$.

Reznik et $a l^{25}$ have provided some insight into the effect of a stress response on nandrolone metabolism. Hypoglycaemia was induced in 10 subjects by intravenous injection of 0.1 $\mathrm{IU} / \mathrm{kg}$ insulin. Urine samples were collected at $0-2,2-4$, and 4-10 hours after the insulin injection. They concluded that hypoglycaemic stress did not significantly alter NA excretion. However, inspection of their data shows that, in certain subjects, NA excretion increased in the first two hours after induction of the hypoglycaemic stress. Had the study included more than 10 subjects, it is likely that there would have been sufficient statistical power to show that the increase in NA in the first two hours after hypoglycaemic stress would have produced a significant finding. Hypoglycaemic stress is associated with the production of glucose counter-regulatory hormones: cortisol, glucagon, growth hormone, and adrenaline. ${ }^{32}$ Cortisol is produced in the adrenal cortex when stimulated by adrenocorticotrophic hormone. The latter also stimulates the production of androgens and mineralocorticosteroids from the adrenal cortex. ${ }^{32}$ It is tempting to speculate that the increased production of adrenal androgens results in increased NA excretion as described above. Further studies need to evaluate whether the increase in adrenal androgens and their aromatisation could produce any changes in NA excretion after traumatic musculoskeletal stress.

\section{Mineral cofactors and herbal products}

There is also a theoretical argument that certain substances not prohibited in sport may alter nandrolone metabolism. For example, the trace element zinc is a cofactor in many enzymic processes in the body. An increase in serum testosterone in men who are marginally zinc deficient has been shown after zinc supplementation. ${ }^{60}$ Also, diets deficient in zinc resulted in a significant decrease in serum testosterone concentration. Therefore it can be concluded that zinc supports testosterone production. ${ }^{60}$ Although there is a linear relationship between serum zinc and serum testosterone concentrations, ${ }^{61}$ it is not known whether supraphysiological doses of zinc are associated with higher levels of testosterone production. Certain athletes are marginally zinc deficient $t^{62}$ because of inadequate intake ${ }^{63}$ and considerable sweat loss. ${ }^{64}{ }^{65}$ As zinc status may not be optimal in these athletes, can zinc supplementation enhance testosterone production and could this increase in testosterone production increase the production of aromatisation intermediates? This question was partially addressed when a zinc/magnesium supplement (30 mg zinc) was given to football players nightly for eight weeks. This treatment increased free and bound serum testosterone by about 33\%. ${ }^{66}$ These findings were not attributed to haemoconcentration because the blood samples were taken 24 hours after exercise. On the basis of the possibility that 19-norsteroid metabolism may be associated with testosterone metabolism and the aromatisation process, it is feasible that zinc supplementation, combined with exercise, may increase nandrolone metabolites in the urine.

The herbal product tribulus terrestris (tribestan), which has been used in Eastern cultures since ancient times to treat impotence and improve libido, is another substance that has been associated with an increased serum testosterone concentration (S Milanov, unpublished work). Could tribestan in combination with exercise increase NA in the urine? Further research is necessary.

\section{CHALLENGING THE IOC CUT OFF CONCENTRATION FOR URINE NA}

Until recently, studies involving large numbers of subjects to determine the physiological range for the concentration of NA in the urine of men and women free of exogenous nandrolone were lacking. Data on the range of NA could only be drawn from the analysis of urine from sedentary and recreational people at rest. ${ }^{15182425}$ The total number of subjects from all these studies is about 150 . No specific mention is made in any of the studies of the age of the male subjects. This is relevant because testosterone production decreases with advancing age. ${ }^{67}$ Therefore one might expect 19 -norsteroid production to decrease also with advancing age, making the age of study populations an important consideration. The amount of NA in the urine from the subjects did not exceed $1 \mathrm{ng} / \mathrm{ml}$, except in the study of Galan Martin et al, ${ }^{29}$ the concerns in which have already been raised.

\section{"There is no explanation by the IOC of why the threshold concentration for NA is higher in women."}

Two recent studies involving larger numbers of sportsmen have provided further evidence. Urine samples collected after exercise in these studies showed that the concentration of NA in the urine increased, and in certain men the concentration of NA was close to the cut off concentration of $2 \mathrm{ng} / \mathrm{ml} .^{27} 28$ Should this be combined with other stressors and possible supplement interventions (mentioned above), the concentration of NA in the urine is most unpredictable.

The IOC have also apparently collected data and measured NA urine excretion in elite male and female athletes at the 1996 Nagano Olympic games, but these data have not been released into the public domain. ${ }^{68}$ It would be beneficial for the IOC data to be made public to support reasoning behind the calculation of cut off concentrations for NA in the urine of men and women. There is also no explanation by the IOC of why the threshold concentration for NA is higher in women. If 
the reason for it is the higher circulating levels of oestrogen, particularly at the time of ovulation, is this not indirect support for the presence of 19-norsteroids as intermediates in the aromatisation of androgens to oestrogen? ${ }^{26}$ Bradford-Hill has stated: "It is the essence of science to disclose both the data upon which a conclusion is based and the methods by which the conclusion is obtained". ${ }^{69}$

The IOC has defended the status quo on nandrolone and confirmed these threshold values of $2 \mathrm{ng} / \mathrm{ml}$ in men and 5 $\mathrm{ng} / \mathrm{ml}$ in women in Monaco in October 1999. ${ }^{70}$ The conditions of strict liability are currently applied in the case of any athlete contravening the above thresholds.

\section{METHODS TO TEST FOR NA}

A solution to the controversy surrounding nandrolone in sport is to develop a testing procedure that can accurately differentiate endogenous nandrolone metabolites from nandrolone that is ingested or injected. The technique of gas chromatography-combustion-isotope ratio mass spectrometry (GC-C-IRMS) to calculate the ${ }^{13} \mathrm{C} /{ }^{12} \mathrm{C}$ ratio is currently being developed as a method to fulfil this purpose. ${ }^{11-73}$ This is based on the principle that natural steroids have a different carbon isotopic signature from synthetic steroids. The ${ }^{13} \mathrm{C} /{ }^{12} \mathrm{C}$ ratio for synthetic nandrolone metabolites is lower than that for endogenous metabolites, therefore administering exogenous nandrolone will lower this ratio. This ratio has also been proposed as a method of detecting the use of synthetic testosterone as an alternative to the testosterone/epitestosterone ratio. ${ }^{71-73}$ However, a potential problem with GC-C-IRMS is the lack of reproducibility and sensitivity because of the low levels of endogenous nandrolone metabolites present in the body. At present, this method can only be applied to "high" concentrations of NA $(60 \mathrm{ng} / \mathrm{ml})$ in the urine. ${ }^{73}$

Le Bizec et $a l^{74}$ has proposed examining the steroid conjugates as an additional criterion to distinguish between the endogenous or exogenous origin of nandrolone metabolites. Endogenous NA was found to be $30 \%$ sulpho-conjugated in contrast with administered nandrolone, which was found to be $100 \%$ conjugated to glucuronic acid when excreted in the urine. $^{74}$

Kintz et $a l^{7576}$ proposed that analysis of hair samples from athletes is another option to consider for detecting the presence of exogenous nandrolone. The analysis of hair samples could be used to accurately verify positive results obtained by gas chromatography-mass spectrometry.

Until the hair sample and GC-C-IRMS techniques have been validated on a large scale, a prudent approach after the detection of NA in urine samples above the cut off concentration is for the athlete to have further blood tests before the sample is declared positive, as is done for athletes with a high testosterone/epitestosterone ratio

\section{CONCLUSION}

The abuse of the steroid testosterone presented a new problem for drug control in sport. ${ }^{42}$ Perhaps the same can now be said for nandrolone. According to the Olympic movement antidoping code, NA is not a prohibited substance. ${ }^{77}$ However, should NA in the urine exceed a certain threshold concentration, the interpretation is that nandrolone has been ingested or injected. There is strong scientific evidence to show that NA can appear in the urine of people free of exogenous nandrolone. Evidence suggests that NA may occur as an intermediate in the aromatisation of testosterone to oestrogen. Recent evidence has shown that the amount of NA in the urine can be regulated by the administration of human chorionic gonadotrophin. Therefore, threshold concentrations for men $(2 \mathrm{ng} / \mathrm{ml})$ and women $(5 \mathrm{ng} / \mathrm{ml})$ as defined by the IOC are still open to debate because conclusive scientific evidence showing how these values may be altered by various physiological stimuli is lacking. In accordance with this,

\section{Take home message}

19-Norandrosterone (NA) is produced endogenously as an intermediate in the aromatisation of androgen to oestrogen. Intense exercise may increase its concentration in the urine. Future laboratory testing methods need to distinguish endogenous from exogenous nandrolone metabolites accurately, as this has important implications for doping control in sport.

multicentre studies need to answer further specific questions on the current urine threshold concentrations for nandrolone metabolites and whether physiological stressors and permitted supplement interventions can alter NA excretion.

\section{Authors' affiliations}

R M N Kohler, M I Lambert, MRC/UCT Research Unit for Exercise

Science and Sports Medicine, Department of Human Biology, University of Cape Town, Sports Science Institute of South Africa, Newlands, South Africa

\section{REFERENCES}

1 Le Bizec B, Monteau F, Gaudin I, et al. Evidence for the presence of endogenous 19-norandrosterone in human urine. Journal of Chromatography B 1999;723:157-72.

2 Ryan A. Anabolic androgenic steroids. Berlin, Heidelberg: Springer-Verlag, 1976:515-33.

3 Dollers C. Therapeutic drugs. Edinburgh: Churchill Livingstone, $1991 ; 2$ :N25-9.

4 Haupt HA, Rovere GD. Anabolic steroids: a review of the literature. Am J Sports Med 1984;12:469-84.

5 Lambert MI, St Clair Gibson A. Anabolic-androgenic steroids: effects on muscle size and strength. South African Journal of Sports Medicine 1995;2:6-9.

6 Titlestad SD, Lambert MI, Schwellnus MP. A survey to determine types and dosages of anabolic androgenic steroids used by competitive bodybuilders in South Africa. South African Journal of Sports Medicine 1994; 1:24-8

7 Hickson RC, Ball KL, Falduto MT. Adverse effects of anabolic steroids. Med Toxicol Adverse Drug Exp 1989;4:254-71

8 Bjorkhem E, Ek H. Detection and quantitation of 19-norandrosterone in urine by isotope dilution-mass spectrometry. J Steroid Biochem Mol Biol 1982; 17:447-51.

9 Belkein L, Shurmeyer T, Hano R, et al. Pharmacokinetics of 19-nortestosterone esters in normal men. J Steroid Biochem Mol Biol 1985;22:623-9.

10 Masse R, Laliberte C, Tremblay L, et al. Gas chromatographic/mass spectrometric analysis of 19-nortestosterone urinary metabolites in man. Biomed Mass Spectrom 1985:12:115-21.

11 Debruyckere G, de Sagher R, De Leenheer A, et al. The impact of nandrolone metabolites occurring in normal male urines, on the cut-off level stipulated for nandrolone doping. In: Gorog S, ed. Proceedings of the fourth symposium on the analysis of steroids, August 1990, Budapest. Budapest: Pécs, Akademie Kiado, 1990:363.

12 Shanzer W, Donike M. Metabolism of anabolic steroids in man synthesis and use of reference substances for identification of anabolic steroid metabolites. Analytica Chimica Acta 1993;275:23-48.

13 Ozer D, Temizer A. The determination of nandrolone and its metabolites in the urine by gas chromatography-mass spectrometry. Eur J Drug Metab Pharmocokinet 1997;22:421-5.

14 Ayotte C. Nutritional supplements and doping controls. IAAF New Studies in Athletics 1999;14:37-42.

15 Dehennin L, Bonnaire Y, Plou P. Urinary excretion of 19-norandrosterone of endogenous origin in man: quantitative analysis by gas chromatography-mass spectrometry. Journal of Chromatography $B$ 1999;721:301-7.

16 Uralets V, Gillette P. Over-the-counter $\Delta^{5}$ anabolic steroids

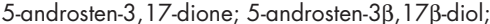
dehydroepiandrosterone; and 19-nor-5-androsten-3,17-dione: excretion studies in men. J Anal Toxicol 2000;24:188-93.

17 Segura J. Letter of information to the heads of $1 O C$ accredited laboratories. Barcelona, August 221996.

18 Catlin D, Leder B, Ahrens B et al. Trace contamination of over-the-counter androstenedione and positive urine test results for a nandrolone metabolite. JAMA 2000;284:2618-21.

19 Debruyckere G, Van Peteghem CH. Influence of the consumption of meat contaminated with anabolic steroids on doping tests. Analytica Chimica Acta 1993;275:49-56.

20 Le Bizec B, Gaudin I, Monteau F, et al. Consequence of boar edible tissue consumption on urinary profiles of nandrolone metabolites. I. Mass 
spectrometric detection and quantitaion of 19-norandrosterone and 19-noretiocholanolone in human urine. Rapid Commun Mass Spectrom 2000;14:1058-65

21 Kicman AT, Brooks RV. A radioimmunoassay for the metabolites of the anabolic steroid nandrolone. J Pharm Biomed Anal 1988:6:473-83.

22 Debruyckere G, de Sagher R, Van Peteghem C. Clostebol-positive urine after consumption of contaminated meat. Clin Chem 1992;38:1869-73.

23 International Olympic Committee. Criteria for reporting low concentrations of anabolic steroids. International Olympic Committee document. 1998:Aug 1:appendix 4

24 Kintz P, Cirimele V, Ludes B. Norandrosterone and Noretiocholanolone: metabolite markers. Acta Clin Belg Suppl 1999;1:68-73

25 Reznik Y, Dehennin L, Coffin C, et al. Urinary nandrolone metabolites of endogenous origin in man: a confirmation by output regulation under human chorionic gonadotrophin stimulation. J Clin Endocrinol Metab 2001;86:146-50.

26 Van Eenoo P, Delbeke FT, de Jong FH, et al. Endogenous origin of norandrosterone in female urine: indirect evidence for the production of 19 -norsteroids as by-products in the conversion from androgen to estrogen. J Steroid Biochem Mol Biol 2001;78:351-7.

27 Robinson N, Taroni F, Saugy M, et al. Detection of nandrolone metabolites in urine after a football game in professional and amateur players: a Bayesian comparison. Forensic Sci Int 2001;122:130-5.

28 Le Bizec B, Bryand F, Gaudin I, et al. Endogenous nandrolone metabolites in human urine. Two year monitoring of professional soccer male players. J Anal Toxicol 2002; in press.

29 Galan Martin AM, Maynar Marino Jl, Garcia de Tiedra MP, et al. Determination of nandrolone metabolites in urine samples from sedentary persons and sportsmen. J Chromatogr B Biomed Sci App 2001;761:229-36

30 Fishman J. Biochemical mechanism of aromatisation. Cancer Res 1982;42:3277-80

31 Longcope C, Kato T, Horton R. Conversion of blood androgens to estrogens in normal adult men and woman. J Clin Invest 1969:48:2191-201.

32 Ganong WF. Review of medical physiology. Connecticut, USA: Lange Medical Books, 1999;17:283;19:345-60

33 Sulcova J, Rafter J, Stuka L. 19-nortestosterone in mouse kidney. Endocrinol Exp 1979;13:225-35.

34 Milewich J, Axelrod A. Testosterone metabolism by placenta microsomes from baboons: identification of 19-nortestosterone and 19-nor-4-androstenedione. J Steroid Biochem Mol Biol1979;10:241-3.

35 Dehennin L, Jondet M, Scholler R. Androgen and 19-norsteroid profiles in human preovulatory follicles from stimulated cycles: an isotope dilution-mass spectrometric study. J Steroid Biochem Mol Biol 1987. 26:399-405

36 Reznik Y, Herrou M, Dehennin L, et al. Rising plasma levels of 19-nortestosterone throughout pregnancy: determination by radioimmunoassay and validation by gas chromatography-mass spectrometry. J Clin Endocrinol Metab 1987;64:1086-8.

37 Uralets V, Gillette P. Over-the-counter anabolic steroids 4 -androsten-3,17-dione, 4-androsten $3 \beta, 17 \beta$-diol, and 19-nor-4-androsten-3, 17-dione: excretion studies in men. J Anal Toxicol 1999:23:357-66.

38 Makin HJL. Biochemistry of steroid hormones. Blackwell Scientific Publications 1975;11:250-71.

39 Hagensen-Jetne AH, Misund J, Hemmersbach P. Determination of urinary norandrosterone excretion in females during one menstrual cycle by GC/MS. Pittcon Conf. 2000:abstract 585 .

40 Mareck-Engelke U, Geyer H, Schanzer W. Recent advances in doping analysis. Cologne: Sport und Buch Strauss, 1998:119.

41 Smals AGH, Pieters GFF, Lozekoot DC, et al. Dissociated response of plasma testosterone and 17 alpha-hydroxyprogesterone to a single or repeated human chorionic gonadotropin administration in normal man. $J$ Clin Endocrinol Metab 1980:50:90.

42 Kicman AT, Brooks RV, Collyer SC, et al. Criteria to indicate testosterone administration. Br J Sports Med 1990;24:253-64

43 Cowan DA, Kicman AT, Walker CJ, et al. Effect of administration of human chorionic gonadotrophin on criteria used to assess testosterone administration in athletes. J Endocrinol 1991;131:147-54.

44 Padron RS, Wischusen J, Hudson B, et al. Prolonged biphasic response of plasma testosterone to a single intramuscular injection of human chorionic gonadotropin. J Clin Endocrinol Metab 1980;50:1000.

45 Pomerantz DK. Human chorionic gonadotropin enhances the ability of gonadotropic hormones to stimulate aromatisation in the testis of the rat. Endocrinology 1981;109:2004.

46 Leder B, Longcope C, Catlin D, et al. Oral androstenedione administration and serum testosterone concentrations in young men. JAMA 2000;283:779-82.
47 Horton R, Tate J. Androstenedione production and the interconversion rates measured in the peripheral blood and studies on the possible site of conversion to testosterone. J Clin Invest 1996;45:301-13.

48 Berkovitz GD, Guerami A, Brown TR, et al. Familial gynecomastia with increased extraglandular aromatisation of plasma carbon $_{19}$-steroids. J Clin Invest 1985;75:1763-9.

49 Gillies H, Derman W, Noakes T, et al. Pseudoephedrine is without ergogenic effects during prolonged exercise. J Appl Physiol 1996:81:2611-17.

50 Sutton JR, Coleman M, Casey JH, et al. Androgen response during physical exercise. BM 1973;1:520.

51 Lamb DR. Androgens and exercise. Med Sci Sports 1975;1:7.

52 Schmitt WM, Kindermann W, Schnabel A. Testosterone blood level and physical exercise. Int J Sports Med 1982;22(suppl):84

53 Viruo A. Hormones in muscular activity. Boca Raton, FL:CRC Press, $1985 ; 4: 85-9$

54 Vogel R. Increase in free and total testosterone during submaxima exercise in normal males. Med Sci Sport Exerc 1985;17:1 19-23.

55 MacConnie SE, Barkan A, Lampman RM, et al. Decreased hypothalamic gonadotrophin-releasing hormone secretion in male marathon runners. $N$ Engl J Med 1986;315:411-17.

56 Kraemer RR, Kilgore JL, Kraemer GR, et al. Growth hormone, IGF-1 and testosterone response to restrictive exercise. Med Sci Sports Exerc 1992;4:1346-52

57 Cumming D, Brunsting L, Strich G, et al. Reproductive hormone increase in response to acute exercise in men. Med Sci Sports Exerc 1986;18:369-73

58 Wilkerson JE, Horvath SM, Gutin B. Plasma testosterone during treadmill exercise. J Appl Physiol 1980;49:249

$59 \mathrm{Nel} \mathrm{S}$. Springbok rugby player tests positive for steroids. Cape Times 2000:Nov 3:26.

60 Prasad AS, Mantzoros CS, Beck FW, et al. Zinc status and serum testosterone levels in healthy adults. Nutrition 1996;12:344-8.

61 Castro-Magana M, Collipp P, Chen S, et al. Zinc nutritional status, androgens and growth retardation. American Journal of Diseases in Children 1981;135:322-5.

62 Khaled S, Brun JF, Micallel JP, et al. Serum zinc and blood rheology in sportsmen (football players). Clin Hemorheol Microcirc 1997; 17:47-58

63 Hawley J, Dennis S, Lindsay F, et al. Nutritional practices of athletes: are they sub-optimal? J Sports Sci 1995; 13:S75-81.

64 Clarkson PM. Minerals: exercise performance and supplementation in athletes. J Sports Sci 1991;9:91-116.

65 Cordova A, Navas FJ. Effect of training on zinc metabolism: changes in serum and sweat zinc concentrations in sportsmen. Ann Nutr Metab 1998;42:274-82

66 Brilla LR, Conte V. Effect of a novel zinc-magnesium formulation on hormones and strength. Journal of Exercise Physiology 2000;3:26-36.

67 Lewis JG, Ghanadian R, Chisholm GD. Serum dihydrotestosterone and testosterone changes with age in man. Acta Endocrinol 1976;82:444-8

68 James VHT. UK Sports Council nandrolone review. London: UK Sports Council, January 2000.

69 Morgan WK. On evidence, embellishment and efficacy. J Eval Clin Pract 1997;3:117-22.

70 Saugy M, Robinson N, Cardis C, et al. Nandrolone metabolites in formal competition tests. FIFA Sports Medical Committee.

71 Shackleton $\mathbf{C H}$, Phillips A, Chang T, et al. Confirming testosterone administration by isotope ratio mass spectrometric analysis of urinary androstanediols. Steroids 1997;62:379-87.

72 Shackleton $\mathbf{C H}$, Roitman E, Phillips A, et al. Androstanediol and 5-androstenediol profiling for detecting exogenously administered dihydrotestosterone, epitestosterone and dehydroepiandrosterone: potential use in gas chromatography isotope ratio mass spectrometry. Steroids 1997; 62:665-73.

73 Mathurin JC, Herrou V, Bourgogne E, et al. Gas chromatography-combustion-isotope ratio mass spectrometry analysis of 19-norsteroids: application to the detection of a nandrolone metabolite in urine. J Chromatogr B Biomed Sci Appl 2001;759:267-75.

74 Le Bizec B, Bryand F, Gaudin I, et al. Endogenous nandrolone metabolites in human urine. Preliminary results to discriminate between endogenous and exogenous origin. Steroids 2002;67:105-10.

75 Kintz P. Hair testing and doping control in sport. Toxicol Lett 1998; 102:109-13

76 Kintz P, Cirimele V, Dumestre-Toulet V, et al. Doping control for nandrolone using hair analysis. J Pharm Biomed Anal 2001;24:1 12530

77 Olympic Movement. Olympic Movement anti-doping code 1999 Appendix A: prohibited classes of substances and prohibited methods. Switzerland: IOC Lausanne, 2001. 